\title{
Analysis and Comparison of SRTM3 DEM and ASTER GDEM v2
}

\author{
SHEN Jing, HAN Wenli, ZHANG Libo, GE Juan \\ National Quality Inspection and Testing Center for Surveying and Mapping Products, Beijing 100830, China
}

KEYWORDS: ASTER GDEM, SRTM3 DEM, digital elevation model, accuracy ABSTRACT:

Global Geographic Information Resources Construction and Maintenance Renewal Project is in urgent need of digital elevation model worldwide. At present, the errors of ASTER GDEMv2 and SRTM3 DEM data widely used are unevenly distributed. In this paper, high-precision and high-resolution WorldDEM data are taken as true values, and flat areas in Turkey and alpine region in Nepal are selected respectively as two test areas A and B. The vertical accuracy of ASTER GDEMv2 and SRTM3 DEM data is verified and compared by using DEM elevation difference numerical analysis, spatial differentiation analysis, slope spectrum curve and other methods. The results show that the two digital elevation models in flat terrain conform to the nominal accuracy, and the vertical accuracy of SRTM3 DEM has an advantage, while the vertical accuracy of ASTER GDEMv2 in high elevation area with large terrain fluctuation is obviously higher than that of SRTM3 DEM, and the area of SRTM3 DEM data accuracy exceeding nominal accuracy is larger. On this basis, the applicability of the two kinds of DEM is analyzed. It is concluded that SRTM3 DEM data with better accuracy should be selected in low altitude plain areas, ASTER GDEM data with higher resolution should be given priority in hilly areas with complex terrain and high mountain areas with severe topographic fluctuations, and ASTER GDEM data can be used to supplement the uncovered areas of SRTM3 DEM。In addition, in areas with high vegetation coverage, the accuracy of the two data is greatly affected, which can be supplemented by ICESAT/GLAS and ICESAT2/GLAS data with strong vegetation penetration ability. The results can provide scientific basis and data support for global space information projects.

\section{INTRODUCTION}

To provide independent, authoritative, unified and efficient geographic information comprehensive services for the implementation of "One Belt, One Road", China will build multi-scale and multi-type geographic information products on a global scale, enabling China to acquire and apply global geographic information resources. International advanced level. To ensure the smooth running of this work, we need to make full use of the existing global public data resources. Among them, Digital Elevation Model (DEM) is an important public data resource, which is important data for data processing and various geoscience analysis, in topographic and geomorphological analysis, hydrological analysis, climate change research, disaster monitoring, civil engineering. Engineering and other aspects have been widely used (Tang Guoan et al., 2005), and the current global DEM is becoming more and more accurate, the spatial resolution of data is getting higher and higher, and the spatial coverage covers all corners of the world. Among the global DEM products, the terrain data generated by the SRTM system on the Space Shuttle Endeavour launched by the United States on February 11, 2000, covers more than $80 \%$ of the earth's surface. It can be divided into SRTM1 and SRTM3, respectively, with corresponding spatial resolutions of $30 \mathrm{~m}$ and $90 \mathrm{~m}$. The SRTM3 has a nominal absolute elevation accuracy of $16.00 \mathrm{~m}$ (LE90) and a relative elevation accuracy of $10.00 \mathrm{~m}$ (LE90). Another global DEM product is ASTER GDEM, which is based on the "Advanced Spaceborne Thermal Emission and Anti-radiation Meter (ASTER)" data generation and is the only high-resolution DEM data covering the global land surface. The data covers all land areas between $83^{\circ}$ north latitude and $83^{\circ}$ south latitude, reaching $99 \%$ of the Earth's land surface. Its global spatial resolution is about $30 \mathrm{~m}$ and its vertical accuracy is $20 \mathrm{~m}$. The latest version is Processed ASTER GDEM V2. The accuracy of both SRTM3 and ASTER GDEM V2 has always been one of the hot spots of interest.

Many scholars have verified the accuracy of ASTER GDEM V2 and SRTM3 DEM data. According to the verification data used, the existing research can be divided into four types. The first is to use the ICESat/GLAS data to carry out comparative verification (Wu Wenjiao et al., 2017). The second is to use the GPS field measurement control point (BROWN, 2005). The 
third is to use the existing high-precision data to compare the two, of which 1:50,000 basic mapping data is used more (Guo Xiaoyi et al., 2011; Yan Yechao, 2008; Cai Qinghua, 2009). The last one is that there is no third-party data, and only the distribution characteristics of the elevation difference of the two types of data are statistically analyzed (Zhao Guosong et al., 2012; Wu Jianqiang et al., 2014;). In this paper, high-precision WorldDEM data (spatial resolution is $12 \mathrm{~m}$, absolute elevation accuracy is $10 \mathrm{~m}$ ) as the reference data, the vertical accuracy and applicability of ASTER GDEM v2 and SRTM3 DEM data are selected from two overseas flat and high mountain regions. analysis.

\section{TEST AREA}

The test area is two alpine and flat areas with typical topographical features, located in Nepal and Turkey.

1). Nepal Experimental Area (hereinafter referred to as Test Area A). The test area $\mathrm{A}$ is located at $85.746^{\circ}-85.85^{\circ}$ east longitude, $27.626^{\circ}-27.537^{\circ}$ north latitude, about $10 \mathrm{~km}$ wide from east to west, about $10 \mathrm{~km}$ long from north to south, and the area is about $100 \mathrm{~km} 2$. The test area is mainly hilly landform, north high and low south, the highest elevation is $2205 \mathrm{~m}$, the lowest elevation is $573 \mathrm{~m}$, and the average elevation is $1331 \mathrm{~m}$. 2). Turkey Test Area (hereinafter referred to as Test Area B). The test area $\mathrm{B}$ is located at $29.126^{\circ}-29.245^{\circ}$ east longitude, $40.918^{\circ}-41.008^{\circ}$ north latitude, about $10 \mathrm{~km}$ wide from east to west, about $10 \mathrm{~km}$ long from north to south, and the area is about $100 \mathrm{~km} 2$. The test area is located at the eastern end of the Balkan Island, adjacent to Istanbul, the entrance to the Black Sea, when the European and Asian traffic is important. The terrain in the test area is relatively flat and mainly flat, with a maximum elevation of $432 \mathrm{~m}$, a minimum altitude of $1 \mathrm{~m}$ and an average elevation of $160 \mathrm{~m}$.

The two test areas have three data: ASTER GDEM v2, SRTM3 DEM and WorldDEM. Among them, WorldDEM products are mainly based on the global SAR image database collected by TerraSAR-X satellite and TanDEM-X satellite, and its accuracy is close to that of laser radar products.

\section{RESEARCH METHODS}

To evaluate the vertical accuracy of SRTM and ASTER GDEM data, the elevation difference between WorldDEM data, SRTM3 DEM, and ASTER GDEM data is statistically analyzed. The statistical parameters include maximum error, minimum error, mean error, medium error, and standard deviation. Among them, the average error can reflect the systematic error of the two kinds of DEM data to be evaluated. The absolute error mean can prevent the positive and negative phase difference in the calculation of the average error. The absolute magnitude of the reaction error, the standard deviation is very sensitive to extra large and very small errors. The root error can reflect the overall size of the error. Then the spatial distribution of the elevation difference of the two DEM data is counted. Finally, the slope grading of the two DEM data is calculated, and the slope spectrum map and the slope spectrum map are generated. Compared with the true DEM curve, the two DEM data are used to maintain the topographical features and detailed information, and the slopes of SRTM3 and ASTER GDEM are obtained. The spectrum is subtracted from the slope of World DEM respectively, and the slope information loss maps of SRTM3 and ASTER GDEM are obtained, and the degree of loss of the terrain slope by the two DEMs is visually compared.

\section{Test and analysis}

The elevation accuracy evaluation of ASTER GDEM and SRTM3 DEM is preferably based on the measured point elevation as assuming true value, but this requires a lot of field work. Due to time, funding and other factors, this study can not carry out field sampling test, using the elevation value of WorldDEM as a reference to verify the data elevation value of ASTER GDEM, SRTM3 DEM, the main methods include DEM elevation difference numerical analysis, elevation difference Spatial differentiation analysis, slope spectrum curve, etc.

\subsection{ERROR OF DEM ELEVATION}

Table1 Test area A elevation differences

unit: $\mathrm{m}$

\begin{tabular}{cccccc}
\hline & $\begin{array}{l}\text { Maxim } \\
\text { um } \\
\text { error }\end{array}$ & $\begin{array}{l}\text { Minim } \\
\text { error }\end{array}$ & $\begin{array}{l}\text { Meanva } \\
\text { lue }\end{array}$ & $\begin{array}{l}\text { Mediu } \\
\text { error }\end{array}$ & $\begin{array}{l}\text { Standa } \\
\text { rd } \\
\text { deviati } \\
\text { on }\end{array}$ \\
\hline ASTER & 96.48 & 0.00 & 11.66 & 15.48 & 10.19 \\
GDEM & 139.62 & 0.00 & 20.34 & 24.94 & 14.44 \\
\hline SRTM3 & 139 & & & &
\end{tabular}

\subsection{Elevation difference space differentiation}

The elevation difference between ASTER GDEM2, SRTM3

DEM and WorldDEM data is extracted separately, and the 
Table2 Test area B elevation differences

unit: $m$

\begin{tabular}{cccccc}
\hline & $\begin{array}{l}\text { Maximu } \\
\text { m error }\end{array}$ & $\begin{array}{l}\text { Minimu } \\
\text { m error }\end{array}$ & $\begin{array}{l}\text { Mean } \\
\text { value }\end{array}$ & $\begin{array}{l}\text { Mediu } \\
\text { error }\end{array}$ & $\begin{array}{l}\text { Standard } \\
\text { deviation }\end{array}$ \\
\hline ASTER & 30.49 & 0.00 & 4.01 & 5.27 & 3.42 \\
GDEM & 30.49 & 0.00 & 2.91 & 3.9 & 2.61 \\
\hline
\end{tabular}

elevation difference is 5 levels. The statistical information of the obtained elevation difference is shown in Table 3 and Table 4.It can be seen from Table 1 that nearly $60 \%$ of the elevation difference of ASTER GDEM in test area A is distributed in the 1st-level elevation difference zone $(0-10.37 \mathrm{~m})$, and the elevation difference of 1 st and 2 nd grade $(0-20.66 \mathrm{~m})$ accounts for all Nearly $90 \%$ of the elevation difference indicates that the data can basically reach the nominal vertical accuracy in areas with high altitude fluctuations. The elevation difference of SRTM3 DEM is mainly distributed in the level 2 (10.37-20.66m) elevation difference band, and the elevation difference of level 1 and level 2 only accounts for $60 \%$, and $40 \%$ of the data area vertical precision exceeds the nominal value. . In this alpine landform area, the vertical accuracy of the ASTER GDEM is better than that of the SRTM3 DEM, which is consistent with the conclusions of the literature (WU Jian-qiang,2014).

It can be seen from Table 4 that in the test area B with flat terrain, the vertical accuracy of ASTER GDEM v2 is worse than that of SRTM3 DEM, but both achieve the nominal accuracy.

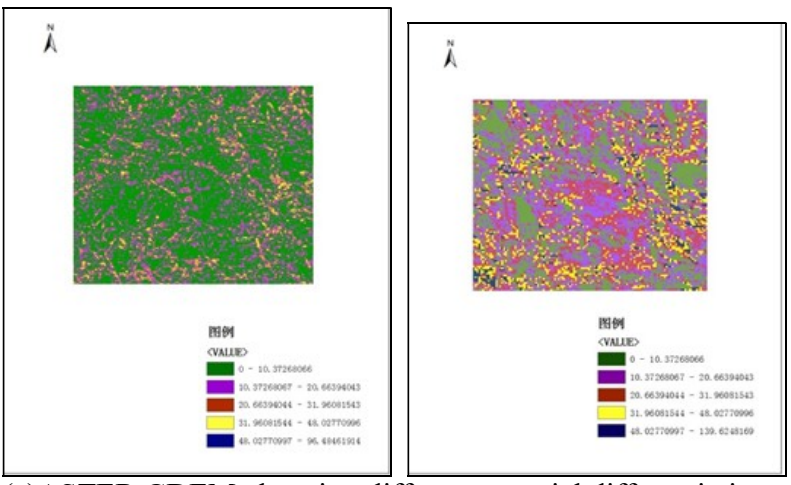

(a)ASTER GDEM elevation difference spatial differentiation

(b) SRTM3 DEM elevation difference spatial differentiation

Figure 1 ASTER GDEM and WorldDEM data elevation difference spatial differentiation in test area A

It can be seen from Fig. 1 that the elevation difference of ASTER GDEM is mainly distributed in the range of $0-10$ meters, while the elevation difference of SRTM3 DEM is mainly distributed in the range of 10-20 meters, and the accuracy of ASTER GDEM in test area A is higher than that of SRTM3 DEM. In Figure 2, the elevation differences of the two
DEMs are similar, and the difference in accuracy is not obvious.

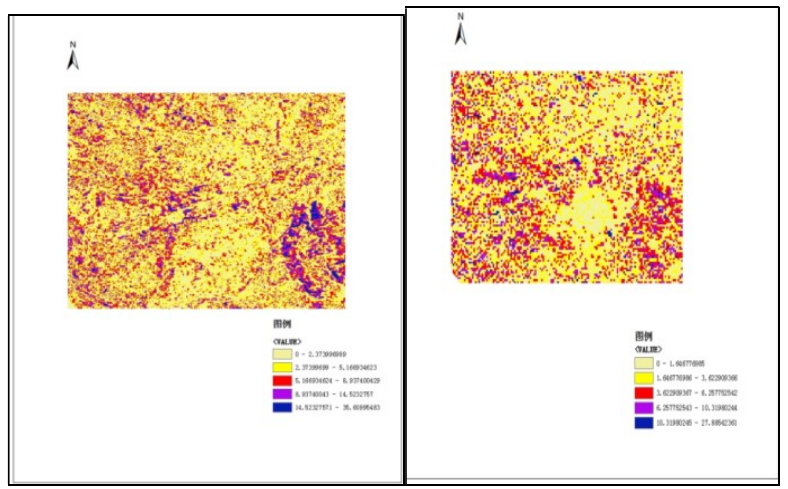

(a) ASTER GDEM elevation difference spatial differentiation

(b) SRTM3 DEM elevation difference spatial differentiation

Figure 2 ASTER GDEM and WorldDEM data elevation difference spatial differentiation in test area $\mathrm{B}$

\subsection{Comparision of slope spectrum}

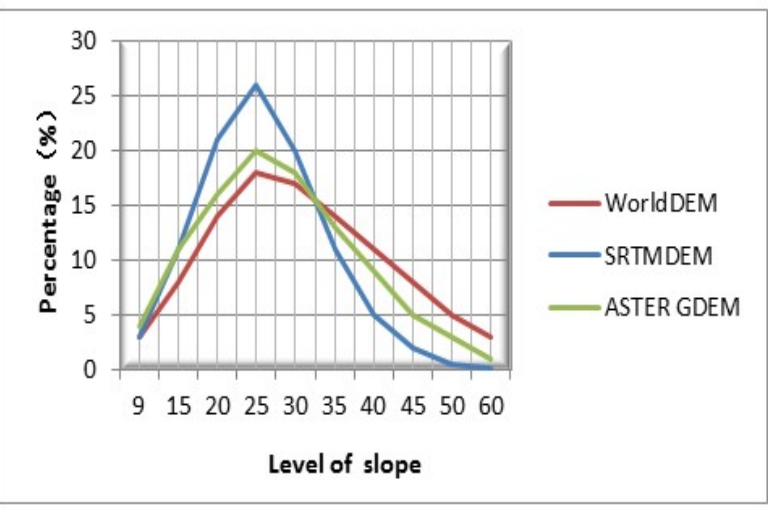

Figure 5 Slope spectrum of three DEMs in test area A

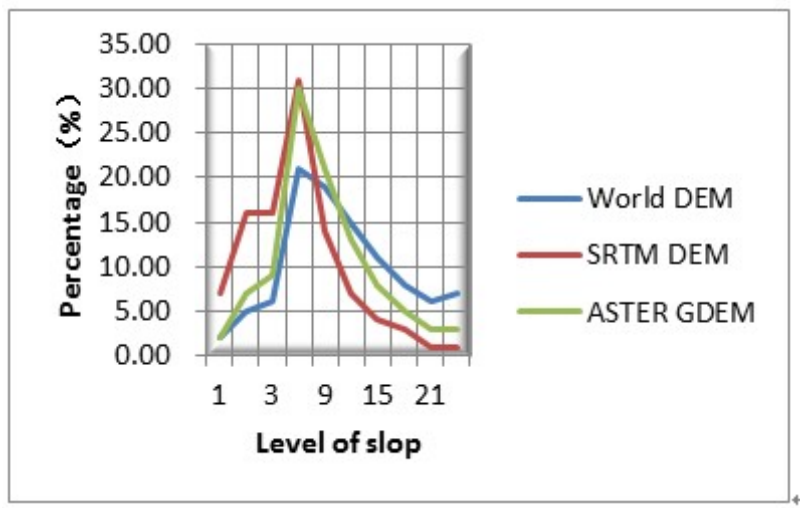

Figure 6 Slope spectrum of three DEMs in test area B

It can be seen from Fig. 5 that the peak value of the slope spectrum of SRTM3 DEM is left-biased, and the peak value is increased, and the slope distribution is relatively concentrated. This shows that due to the relatively small spatial resolution, 
compared with WorldDEM, the description of the detailed features of the terrain is poor, and the terrain has a gentle effect. The slope gradually becomes gentle, the proportion of the gentle slope increases, and the steep slope takes up. The proportion is decreasing. Compared with SRTM3 DEM, the slope curve of ASTER GDEM is close to that of WorldDEM, and it maintains better features for terrain detail.

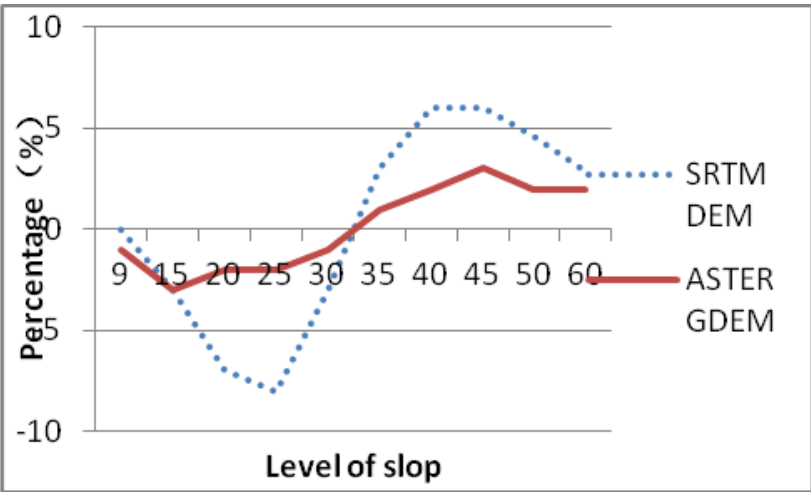

Figure 7 Slope loss statistical graph of test area A

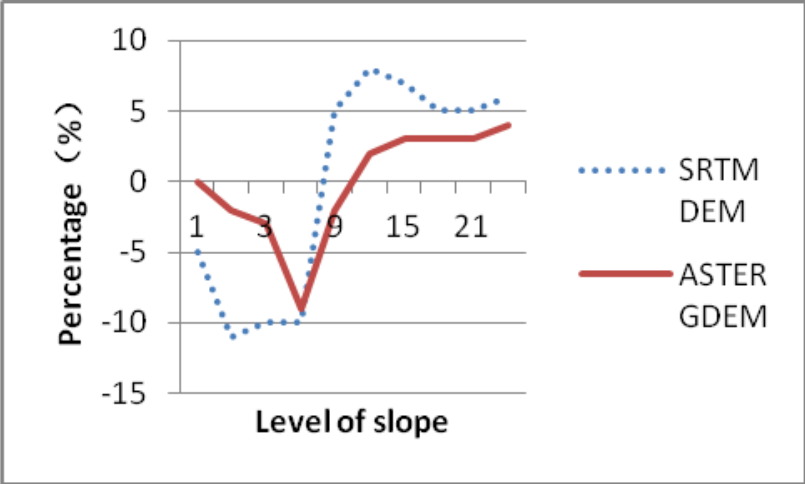

Figure 8 Slope loss statistical graph of test areaB

Through the previous slope analysis, it can be seen that SRTM3 DEM and ASTER GDEM have lost the description of the surface slope information, lost the steep slope information, and increased the gentle slope information. The abscissa indicates the grade of the slope, and the ordinate indicates the percentage of the number of grids where the slope information is lost. Where, a negative value indicates the percentage of the grid of the missing steep slope information, and a positive value indicates the percentage of the grid of the increased gentle slope information.It can be seen from Fig. 9 and Fig. 10 that the aspect spectrum map can visually observe the difference in the slope direction extracted by the three DEMs in the two plots. From a numerical point of view, the percentage of grid area in each direction of ASTER GDEM and World DEM is relatively close, while the value difference between SRTM3 DEM and the two directions is relatively large. According to the sampling area, the numerical difference of the three DEM data in the test area $\mathrm{B}$ is smaller than that in the test area $\mathrm{A}$.

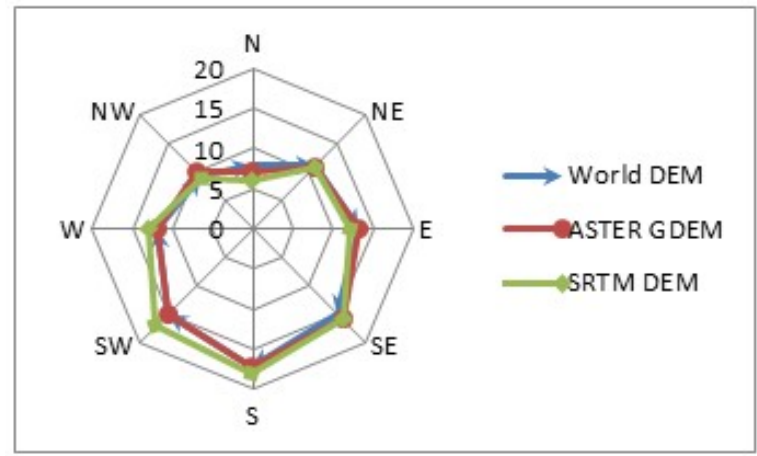

Figure 9 Slope spectrum of test area A

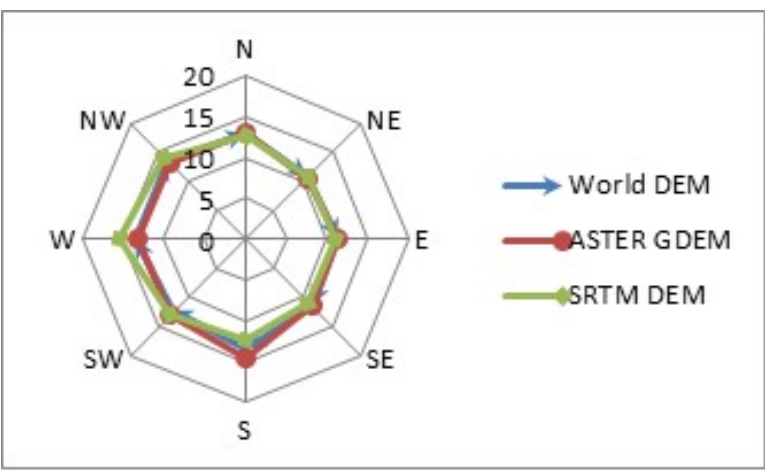

Figure 10 Slope spectrum of test area B

\section{CONCLUSION}

Although SRTM3 DEM has a large single point elevation error in mountainous areas, it has a higher degree of description of landform morphology and elevation variation. Although the single point elevation error is small in the Ping area, the description of landform morphology and elevation variation is better. difference. This is because in the mountainous area, the terrain structure is complex, the terrain relief and cutting depth are large, and the resolution of the SRTM3 DEM cannot meticulate the terrain fluctuations. In addition, due to the flaws of the radar interferometry itself, in some areas with steep mountains, the slope of the back slope of the mountain may cause radar shadows and cause data loss. Therefore, it is recommended that SRTM3 DEM data with better accuracy should be used in low-altitude plain areas. ASTER GDEM data with high resolution should be given priority in low-altitude hilly terrain with complex resolution. In high mountain areas with severe terrain fluctuations, SRTM3 DEM data has a wide 
range of cavities. At this time, the SRTM3 DEM data is optimized and filled with ASTER-GDEM. For the SRTM3 DEM uncovered area, ASTER GDEM can be used for supplementation; in addition, in areas with high vegetation coverage, the accuracy of both data is greatly affected, and can be supplemented by ICESAT/GLAS and ICESAT2/GLAS data. This paper only analyzes the relationship between terrain and the accuracy of two kinds of DEM data. The next step is to study the correlation between the accuracy of the two and the type of surface coverage.

\section{REFERENCE}

[1] Tang guoan, Liu xuejun,Lv guonian. Principles and Methods of Digital Elevation Model and Geoscience Analysis [M]. Peking: Science Press, 2005.

[2] Gou J J, Wang F, Luo M L, et al. Fractal characteristics of channel junctions (CJs) based on DEM[J]. Journal of Soil and Water Conservation, 2016,30(3): 109-114.

[3] Chen J B, Li H, Chen W H, et al. Auto-classification of geomorphological types based on DLG and DEM for Fujian province $[\mathrm{J}]$. Journal of Geo- Information Science, 2013, 15(1):75-80.

[4] Sun G, Ranson K J, Kharuk V I, et al. Validation of sur-face height from shuttle radar topography mission using shuttle laser altimeter[J].Remote Sensing of Environment, 2003, 88: 401-411.

[5] Slater J A, Heady B, Kroenung G, et al.Global Assessment of the New ASTER Global Digital Elevation Model[J].Photogrammetric Engineering and Remote Sensing, 2011,77(4): 335-349.

[6] Abrams M, Bailey B, Tsu H, et al. The ASTER Global DEM[J].Photogrammetric Engineering and Remote Sensing, 2010,76(4):344-348.

[7] LI Zhenhong, LI Peng, DING Dong, WANG Houjie. Research Progress of Global High Resolution Digital Elevation Models. GEOMATICS AND INFORMATION SCIENCE OF WUHAN UNIVERS, 2018, 43(12): 1927-1942.

[8] Wu W J, Zhang S F, Zhao S M. 2017. Analysis and comparison of SRTM1 DEM and ASTER GDEM V2 data Journal of Geo-information Science, 19(8):1108- 1115.

[9] Yan YC, Zhang SW, Yue SP.Evaluation of SRTM data quality in area of undulating hills of Northeast China.Journal of the Graduate School of the Chinese Academy of Sciences , 2008, 25(1):41-46

[10] CAI Qing-hua, YANG Qin-ke .Comparison of Terrain Representation of SRTM and Topographic Derived DEMs[J].2009(3):183-187

[11] WU Jian-qiang, WANG Yi-XIANG,YANG Yu, YANG Yi. Accuracy Assessment to Elevation of Linglong Mountain and Its Surrounding Areas Simulated by SRTM3 and ASTER GDEM Model[J].JOUNAL OF SOUTHWEST FORESTRY UNIVERSITY, 2014,34 (2): 72-77.

[12] Brown C G, Sarabandi J K, Pierce L E. Validation of the Shuttle Radar Topography Mission height data[J]. IEEE Transactions on Geoscience and Remote Sensing, 2005,43 (8):1707-1715.

Table 3 ASTER GDEM, SRTM3 DEM and WorldDEM data elevation difference statistics in test area A

\begin{tabular}{lccccccc}
\hline & \multicolumn{3}{c}{ ASTER GDEMv2 } & & \multicolumn{2}{c}{ SRTM3 DEM } \\
\cline { 2 - 8 } & $\begin{array}{l}\text { Number } \\
\text { pixels }\end{array}$ & Area $\left(\mathrm{km}^{2}\right)$ & $\begin{array}{l}\text { Percentage } \\
(\%)\end{array}$ & $\begin{array}{l}\text { Number } \\
\text { pixels }\end{array}$ & of & Area $\left(\mathrm{km}^{2}\right)$ & Percentage (\%) \\
\hline Level 1(0-10.37) & 68452 & 61.60 & 57.90 & 3776 & 30.60 & 28.80 \\
Level 2(10.37-20.66) & 35893 & 32.30 & 30.40 & 4099 & 33.20 & 31.20 \\
Level 3(20.66-31.96) & 10592 & 9.50 & 8.90 & 3160 & 25.60 & 24.10 \\
Level 4(33.96-48.03) & 2899 & 2.60 & 2.40 & 1595 & 12.90 & 12.10 \\
Level 5(48.03above) & 460 & 0.40 & 0.40 & 514 & 4.20 & 3.90 \\
\hline
\end{tabular}

NOTE: ASTER GDEMv2 372*318 pixels $\quad$ SRTM3 DEM 124*106 pixels

Table 4 ASTER GDEM, SRTM3 DEM and WorldDEM data elevation difference statistics in test area B

\begin{tabular}{|c|c|c|c|c|c|c|c|}
\hline & \multicolumn{3}{|c|}{ ASTER GDEMv2 } & \multicolumn{4}{|c|}{ SRTM3 DEM } \\
\hline & $\begin{array}{l}\text { Number of } \\
\text { pixels }\end{array}$ & Area $\left(\mathrm{km}^{2}\right)$ & $\begin{array}{l}\text { Percentage } \\
(\%)\end{array}$ & $\begin{array}{l}\text { Number } \\
\text { pixels }\end{array}$ & of & Area $\left(\mathrm{km}^{2}\right)$ & $\begin{array}{l}\text { Percentage } \\
(\%)\end{array}$ \\
\hline Level 1(0-1.5) & 35932 & 32.30 & 25.50 & 5753 & & 46.60 & 36.70 \\
\hline Level 2(1.5-3.5) & 39444 & 35.50 & 28.10 & 5080 & & 41.10 & 32.40 \\
\hline Level 3(3.5-6.0) & 31867 & 28.70 & 22.70 & 2988 & & 24.20 & 19.10 \\
\hline Level 4(6.0-10.0) & 22636 & 20.40 & 16.10 & 1532 & & 12.40 & 9.80 \\
\hline Level 5(10.0 above) & 10627 & 9.60 & 7.60 & 323 & & 2.60 & 2.00 \\
\hline
\end{tabular}

NOTE: ASTER GDEMv2 431*326 pixels SRTM3 DEM 144*109 pixels 